\title{
POLÍTICAS SEXUADAS NA TURQUIA: UM NOVELO EMARANHADO*
}

\author{
Deniz Kandiyoti
}

\section{RESUMO}

A Turquia é frequentemente apontada como o único país predominantemente muçulmano com constituição laica e com um Código Civil que não obedece à xaria, sendo que o movimento de mulheres obteve vitórias importantes em matéria de reformas jurídicas no início dos anos de 2000. Observa-se, entretanto, um crescente abismo entre direitos formais e direitos reais após a esmagadora vitória do AKP, em 2007. Por conta das divisões que atravessam as fileiras feministas - particularmente acerca da questão do véu - o artigo se pergunta sobre a validade de tais conquistas'.

Palavras-chaves: Turquia; igualdade entre os sexos; política internacional; religião; política de gênero.

\section{POLITIQUES SEXUÉES EN TURQUIE: UN ÉCHEVEAU INEXTRICABLE}

\section{RÉSUMÉ}

La Turquie est souvent mise en exergue comme le seul pays à majorité musulmane ayant une Constitution laïque et un Code civil n'obéissant pas à la charia, et le mouvement des femmes y a remporté d'importantes victoires en matière de réformes juridiques au début des années 2000. On observe toutefois un fossé croissant entre droits formels et droits réels suite à l'écrasante victoire électorale de l'akp en 2007. Au vu des divisions qui traversent les rangs féministes - sur la question du voile, notamment - l'article s'interroge sur la validité de ces acquis. Mots-clés: Turquie; égalité des sexes; politique internationale; religion; politique de genre.

* Traduzido da versão francesa para o português por Vitor Chaves de Souza. Revisão da tradução por Tomás Rosa Bueno e Naira Pinheiro dos Santos. O texto original em francês, "POLITIQUES SEXUÉES EN TURQUIE: UN ÉCAVEAU INEXTRICABLE”, Cahiers du Genre, 2012/3 (HS n 3), p. 109-117, foi traduzido do inglês por Jacqueline Heinen.

1 O original em inglês deste artigo foi retirado do site Open Democracy (5 de janeiro de 2011) e traduzido para o francês por Jacqueline Heinen 
Aos 18 de Julho de 2010, o primeiro-ministro da Turquia, Recep Tayyip Erdogan, encontrou-se com organizações femininas não governamentais para uma reunião consultiva no âmbito do "Projeto de iniciativa democrática, de união nacional e de fraternidade" - denominado pela imprensa popular de "iniciativa curda". Sua finalidade é resolver o conflito que grassa no sudeste do país, opondo o Partido dos Trabalhadores do Curdistão (PKK) e o exército turco (COOK, KIRIŞÇI, MIGDALOVITZ 2009). O primeiro-ministro dirigiu-se às mulheres presentes como mães, "cuja voz sufocaria o barulho das balas", engajando-as assim na defesa da paz. Entre as 80 participantes havia membros de organizações não governamentais (ONG) conhecidas pelas suas posições feministas, como a KA-DER e a Fundação para a Solidariedade das Mulheres. Assim, quando chegou o momento das perguntas, algumas participantes questionaram o primeiro-ministro quanto ao motivo pelo qual se dirigia às mulheres exclusivamente como mães, ignorando o fato de que elas são indivíduos de plenos direitos no plano econômico, político e jurídico. Ao que ele retrucou: "Não acredito na igualdade de homens e mulheres. Acredito na igualdade de oportunidades. Homens e mulheres são diferentes e complementares".

Essa resposta mostra que, a despeito da adesão formal da Turquia à $\mathrm{CEDAW}^{2}$, o primeiro-ministro se remetia ao fitrat, preceito islâmico que atribui qualidades e naturezas distintas e divinamente ordenadas a homens e mulheres. As reações das participantes foram amplamente comentadas na imprensa local, referidas como "choque absoluto", "banho de água fria", "espanto total" e "profunda decepção" (PELEK, 2010). Muito mais significativo do que os comentários do primeiro-ministro - um político que, afinal, nunca havia feito segredo das suas tendências conservadoras - foi o sentimento de profunda consternação com os quais foram recebidos. As razões por trás de tal desânimo só podem ser explicadas à luz dos confrontos anteriores do movimento de mulheres com o Estado turco.

\section{UMA LUTA ÁRDUA POR REFORMAS JURÍDICAS}

Muitas vezes a Turquia é apontada como o único país de maioria muçulmana que possui uma Constituição laica e um Código Civil (ado-

Sigla inglesa para Convenção sobre a Eliminação de Todas as Formas de Discriminação contra a Mulher. 
tado em 1926) que rompe com a xaria. O código proíbe a poligamia e o divórcio unilateral, ao passo que reconhece a igualdade dos sexos no que se refere aos direitos de herança e custódia dos/as filhos/as. No entanto, surgiu nos anos de 1980 uma nova geração de feministas que já não se contentam em serem filhas agradecidas à República. Elas atacaram questões que eram anteriormente tabus e que haviam sido cuidadosamente varridas para debaixo do tapete, como a violência doméstica, o assédio sexual e o estupro, e fizeram delas objeto de debate público. A primeira vitória foi obtida em 1990, quando o artigo 438 do Código Penal turco, que reduzia em um terço a pena de violadores se a vítima fosse uma trabalhadora do sexo, foi revogado pela Grande Assembleia Nacional. Seguiu-se então uma grande campanha lançada por mais de 120 ONGs de mulheres em todo o país para reformar o Código Civil e eliminar todas as cláusulas discriminatórias ainda em vigor. A nova versão adotada em novembro de 2001 aboliu a supremacia dos homens na união conjugal e estabeleceu a plena igualdade de homens e mulheres em matéria de direitos do universo familiar, os bens matrimoniais, o divórcio, a custódia de filhos/as, a herança e os direitos de trabalhar e de viajar (ANIL et al., 2005).

De 2002 a 2004 uma vigorosa campanha de três anos liderada por uma coalizão de mulheres e de grupos pelas liberdades sexuais - a Plataforma para a Reforma do Código Penal Turco - resultou na aprovação, em 26 de setembro de 2004, de um projeto de lei que incluía diversas emendas: supressão da redução da pena para "crimes cometidos em nome do direito consuetudinário" (os chamados "crimes de honra"); criminalização do estupro conjugal; abolição do artigo que previa a redução ou suspensão da pena para estupradores e sequestradores que se casassem com as suas vítimas; penalização de infrações sexuais tais como o assédio no local de trabalho; e fim da discriminação entre virgens e não virgens, entre mulheres casadas ou não em caso de crimes sexuais (ILKKARACAN, 2007).

Note-se que após a aceitação da sua candidatura de adesão à União Europeia (EU) em dezembro de 1999 a Turquia precisava colocar o seu sistema jurídico, político e económico em conformidade com as normas da UE. O movimento de mulheres aproveitou certamente a oportunida- 
de para pressionar por mais reformas. No entanto, esta revelou-se uma luta árdua. Desde o início, em abril de 2000, um grupo de deputados do sexo masculino de todos os partidos políticos tentou bloquear o projeto de Código Civil, alegando que a igualdade na família levaria ao caos e à anarquia. Em novembro de 2002, após a vitória eleitoral do Partido da Justiça e do Desenvolvimento (AKP) - autoidentificado como um partido conservador muçulmano - as apostas subiriam ainda mais. Os membros do grupo que havia dado início ao pedido de reforma - o Grupo de Trabalho das Mulheres sobre o Código Penal (WWRG) - fracassaram na tentativa de iniciar um diálogo com o novo governo e tiveram que recorrer a uma campanha pública na mídia, fazendo lobbying para ampliar a sua iniciativa e formar uma grande plataforma nacional.

Embora tenham sido muito criticadas pela imprensa islâmica, que as acusou de serem "sem-vergonhas", tratando-as de "devassas" e "raivosas", elas tocaram num ponto sensível. Quando o conselheiro-chefe do ministério da Justiça opinou que, num país onde todos os homens desejam casar-se com uma virgem, a única saída sensata para uma mulher estuprada seria obviamente casar-se com o seu agressor (mesmo se, quando questionado, admitiu que não conseguia conceber essa hipótese para a sua própria filha), ele provocou um sentimento de repulsa junto à opinião pública. Enquanto o debate se intensificava, soube-se que a Relatora Especial da ONU sobre a Violência contra as Mulheres, Yakin Erturk, era casualmente uma mulher turca. Ela facilitou o encontro de representantes da Plataforma, do Parlamento e da UE para um diálogo sobre o Código Penal, em 10 de dezembro de 2003, numa reunião de importância estratégica, pois resultou na visibilidade e no reconhecimento - ainda que a contragosto- da Plataforma internacional.

No entanto, o AKP tomou suas próprias iniciativas. A apenas um mês da União Europeia ter de emitir um julgamento sobre os progressos realizados pela Turquia no sentido de se adequar às normas da UE, esse partido propôs a recriminalização do adultério. O momento não foi bem escolhido. Essa proposta criou uma tempestade no plnao nacional e espanto no seio da UE. Quando o AKP decidiu bloquear totalmente o pacote de reformas, a UE ameaçou suspender as negociações de adesão (BBC News, 2004). No entanto, os grupos do mundo financei- 
ro - incluindo os capitalistas muçulmanos - não queriam cortar suas relações com a Europa (BBC News 2004). O primeiro-ministro recuou, saindo de um impasse que tomava o rumo de uma verdadeira crise (os mercados haviam começado a cair). Ironicamente, a Turquia havia se adequado à CEDAW sob governos que tinham pouco tempo para as reivindicações feministas.

\section{UM TERRENO ESCORREGADIO?}

O caráter conjuntural dessas vitórias jurídicas, devidas a numa conjunção fortuita de fatores externos e internos (as cláusulas condicionais da UE e esforços conjuntos de mídias liberais e dos grupos de mulheres), atesta a sua fragilidade. As cartas foram redistribuídas em seguida devido: à esmagadora vitória eleitoral do AKP, em 2007, que voltou a ser o partido no poder com uma maioria de $47 \%$; à evaporação da perspectiva da adesão à UE e, ao mesmo tempo, dos meios de pressão que ela poderia ter oferecido; à derrocada do Dogan Media Group, que detinha parte substancial da imprensa liberal (KORKUT, 2010); e a uma forte aspiração geopolítica em favor de uma Turquia muçulmana associada a um modelo exportável de "islã moderado" (APPLEBY, 2010). Um conjunto de elementos a garantir que haja muito pouca chance dessa oportunidade única se repetir.

De fato, a distância entre a legislação progressista da Turquia e as realidades práticas constitui um abismo. O Global Gender Gap Report 2009, publicado pelo World Economic Forum (WEF), classificou a Turquia na posição 129, de um total de 134 países, em termos de igualdade entre homens e mulheres. Somente a Arábia Saudita, Benin, Paquistão, Chade e lêmen ficaram em posições inferiores. Além disso, a Turquia vem caindo no ranking: mantinha a posição 105 em 2006; foi para 121 em 2007 e 123 em 2008. O mais recente relatório de 2010 classifica a Turquia em 126, bem perto do fundo da tabela. (HAUSMANN, TYSON, ZAHIDI, 2010).

Yesim Arat (2010) especula se o país não estaria vivendo um paradoxo democrático: o exercício das liberdades religiosas, encorajado por governos democraticamente eleitos, poderia ser realmente acompanhado de ameaças potenciais ou reais à igualdade de gênero? Como 
ela prontamente reconhece, o que está em jogo não é a liberdade religiosa em si. Desde o advento da democracia multipartidária em 1950, os religiosos se estabeleceram na vida política turca. Diversos partidos de centro-direita ligaram-se por apadrinhamento a líderes influentes das comunidades religiosas (tarikat), dos quais esperavam, em troca, apoio político. Após a década de 1980, com a adoção de políticas neoliberais, a caridade substituiu as já combalidas redes de segurança social, conferindo às comunidades religiosas, na escala local, um papel chave no trabalho contra a pobreza e na implementação de novas formas de solidariedade social (TUĞAL, 2006). Essas comunidades religiosas tornaram-se atores integrantes da sociedade civil graças aos recursos que manejam e jogando com as expectativas populares, apesar do mal estar difuso causado pela sua crescente influência política - desprovida de qualquer transparência (TUĞAL, 2006). Além disso, a aversão provocada pelo golpe militar de 12 de setembro de 1980 garantiu o alinhamento de vários grupos eleitorais, liberais e islamistas, com o programa de “democratização" liderado pelo AKP - mesmo isso implicando exigir das mulheres que encontrassem virtudes no princípio islâmico da fitrat.

\section{DILEMAS FEMINISTAS: AS QUESTÕES QUE UNEM E AQUELAS QUE DIVIDEM}

Enquanto isso, confrontada aos seus próprios dissabores multiculturais, à islamofobia latente (e aberta) e por resquícios de culpa colonial, a opinião pública no Ocidente voltou-se para uma única questão: a proibição do uso do véu nas universidades e edifícios públicos - proibição que acabou sendo revogada (Seibert 2010). Isso foi apresentado como uma violação dos direitos humanos - do direito fundamental à liberdade religiosa - por parte de uma elite laica autoritária e intransigente.

As respostas na própria Turquia foram mais nuançadas. Como era de se esperar, a questão dividia as feministas laicas entre as que defendiam o direito ao véu como um direito individual inalienável de escolher o próprio traje (e as próprias crenças), e as que temiam que isso fosse apenas a ponta visível do iceberg, em relação à igualdade das mulheres inscrito no sistema jurídico (SAKTANBER, ÇOBANOĞLU, 2008). Ficava cada vez mais evidente, no entanto, que muitas mulheres 
que havia optado por usar o véu, não estavam mais inclinadas do que as suas irmãs laicas a tolerar a poligamia ou a se submeter docilmente às discriminações.

Numa sociedade que mantém o privilégio masculino a qualquer custo, as mulheres de todos os grupos possuem muitos pontos em comum. Quando, na década de 1990, o município de Istambul propôs a implementação de ônibus reservados às mulheres, as opiniões femininas se dividiram. Enquanto algumas temiam que isso trouxesse de volta os tristes tempos da segregação sexual, outras se regozijaram com tal projeto, não por respeito a convenções islâmicas, mas por puro cansaço de ter de lutar cotidianamente nos transportes mistos. Elas só queriam viajar em paz.

A posição precária das mulheres como intrusas nos espaços públicos voltou à tona no verão de 2008, quando uma mãe de 28 anos de idade, com dois filhos, que estava pescando na ponte de Gálata em Istambul foi acusada de "indecência" por outro pescador, segundo os termos do artigo 225 do Código Penal turco. O tribunal confirmou a acusação e aplicou uma pena de prisão de seis meses, reduzida para cinco meses, e finalmente comutada porque ela nunca sofrera nenhuma condenação. Isso provocou uma previsível indignação das feministas, que organizaram uma manifestação na ponte, sob a bandeira "Nossos corpos nos pertencem", e difundiram um comunicado de imprensa nesse sentido. Perguntas retóricas precediam a declaração: “As muIheres podem pescar? Elas podem se vestir como quiserem? Elas têm liberdade de movimento?" A resposta era, evidentemente, negativa, já que uma mulher pode ser condenada a 6 meses de prisão por ofender a moralidade pública, enquanto homens que assediam sexualmente mulheres na praça Taksim durante as comemorações de Ano Novo recebem uma multa insignificante. Elas reivindicavam a revogação do artigo 225, cujo conteúdo permite claramente intimidar as mulheres em nome da moralidade pública.

Dado o número não negligenciável de mulheres laicas que, na mídia, na academia e nos círculos feministas, haviam se alinhado à causa comum com as suas irmãs que usavam véu para defender seu direito à liberdade de vestimenta, era de se esperar que o gesto fosse retribuído 
nessa ocasião. No caso, a resposta foi bastante tímida. Além das previsíveis acusações de impudor por parte de certos setores da imprensa (que fustigavam sobretudo a pescadora, por estar na ponte), poucas mulheres que usam véu - exceto por uma minoria que teve a coragem de se mostrar coerente na questão dos direitos - dispuseram-se a envolver-se. Claro, muitas delas talvez se sentissem pouco à vontade diante do comportamento de uma mulher que escolhera misturar-se com homens desconhecidos num espaço público geralmente considerado como seu feudo. Há, no entanto, uma grande diferença entre se abster de tal comportamento e aprovar o fato de que um Estado repressivo recorra à força (nos termos do Artigo 225) contra mulheres que se arrisquem nesse espaço. Muitas mulheres que optaram pelo uso do véu têm plena consciência dessas diferenças elementares. Algumas argumentam, corretamente, que tal escolha só tem sentido em contextos em que nada as obrigue a fazê-lo. Outras, em compensação, são tentadas a concordar com medidas repressivas para 'manter as mulheres no seu lugar'.

Como resultado das reformas republicanas e das lutas feministas que se seguiram as mulheres turcas têm hoje muito a perder. Elas conseguiram, contra todas as probabilidades, reduzir e corroer os direitos e privilégios masculinos - no papel, no texto da lei, senão na sociedade em geral. Elas se perguntam agora ansiosamente se conseguirão preservar essas conquistas.

\section{REFERÊNCIAS}

ANIL, Ela et al. Turkish Civil and Penal Code Reforms from a Gender Perspective: The Success of two Nationwide Campaigns. Istanbul: WWHR, 2005.

APPLEBY, Scott R. Of Fundamentalisms, Secular and Otherwise. Open Democracy, 27 Setembro, 2010.

ARAT, Yeşim. Religion, Politics and Gender Equality in Turkey: Implications of a Democratic Paradox?. Third World Quarterly, vol. 31, n 6, 2010.

BBC NEWS. EU Demands New Turkish Penal Code. BBC News, 20 September, 2004. COOK, Steven, KIRIŞÇI, Kemal, MIGDALOVITZ, Carol. The Kurdish Opening in Turkey: Origins and Future. The Carnegie Endowment for International Peace Tuesday, Dezembro 1, Washington, DC, 2009. 
HAUSMANN, Ricardo, TYSON, Laura D., ZAHIDI, Saadia (Eds.). The Global Gender Gap report. Geneva: World Economic Forum, 2010.

ILKKARACAN, Pinar. Reforming the Penal Code in Turkey: The Campaign for the Reform of the Turkish Penal Code from a Gender Perspective. Brighton: Institute of Development Studies, 2007.

KORKUT, Tolga. Dogan Media Group Appeals Heavy Tax Fine. Bianet News, 20 Agosto, 2010.

PELEK, Semra (2010). Women's Rights Defender Ilkkaracan: We Insist on our Requests. Bianet News, 20 Julho, 2010.

SAKTANBER, Ayşe, ÇOBANOĞLU, Gül. Veiling and Headscarf: Scepticism in Turkey. Social Politics, vol. 15, $\mathrm{n}^{\circ} 4,2008$.

SEIBERT, Thomas. Headscarf ban Fizzles out in Turkey. The National, 13 Outubro, 2010. TUĞAL, Cihan Z. The Appeal of Islamic Politics: Ritual and Dialogue in a Poor District in Turkey. Sociological Quarterly, vol. 47, n², 2006. 